\title{
PROJETO ESTRUTURAL DE UMA RESIDÊNCIA DE DOIS PAVIMENTOS
}

Marcelo Antonio Krüger ${ }^{1}$

Gilsinei da Silva ${ }^{2}$

\section{RESUMO}

Este trabalho abordou tudo o que foi visto nas disciplinas estudadas no decorrer do curso de Engenharia Civil, referentes ao dimensionamento de projeto estrutural em concreto armado, com o foco de elaborar o dimensionamento de um projeto estrutural de uma residência unifamiliar de dois pavimentos construída em alvenaria tradicional, com o aparo do software Eberick, do qual, é um programa computacional destinado aos profissionais da Engenharia, que é produzido com o intuito de ser uma ferramenta bastante útil no que diz respeito ao dimensionamento de um projeto estrutural, levando em consideração principalmente o tempo levado para a concepção do projeto. O dimensionamento de uma estrutura de concreto armado é o conjunto de atividades de projetos que conduz à determinação das dimensões das peças e posteriores armaduras de aço, bem como o detalhamento dessas armaduras no interior das peças e em suas ligações, a fim de suportar as ações atuantes na edificação. Este processo deve atender às disposições das normas técnicas pertinentes, para que a estrutura tenha uma garantia adequada de segurança à ruptura e um bom andamento nas condições previstas de utilização. Para o objetivo geral, o propósito deste trabalho é a realização com o auxílio do software Eberick, o dimensionamento estrutural de uma residência unifamiliar de dois pavimentos em concreto armado. A metodologia deste trabalho teve como base pesquisas bibliográficas em livros, normas técnicas, artigos; assim fornecendo todo o seu embasamento teórico e normativo para todas as etapas presentes neste Trabalho de Conclusão de Curso. Palavras-Chave: Eberick. Projeto estrutural. Concreto armado.

\footnotetext{
${ }^{1}$ Acadêmico do Curso de Engenharia Civil da Universidade Alto Vale do Rio do Peixe (UNIARP).

2 Professor Orientador. Graduado em Engenharia Civil, pela Universidade Federal de Santa Catarina, Especialista em Administração, Gestão Pública e Políticas Sociais, pela Faculdade Dom Bosco, e docente do Curso de Engenharia Civil da Universidade Alto Vale do Rio do Peixe.
} 


\section{ABSTRACT}

This work deals with everything that was seen in the disciplines studied in the course of the course related to the design of structural design in reinforced concrete, with the focus of elaborating the design of a structural design of a single - family dwelling of two floors built in traditional masonry, with the of Eberick software, of which it is a computer program designed for Engineering professionals, which is produced with the intention of being a very useful tool in the dimensioning of a structural project, taking into account, in particular, the time taken for the project design. The dimensioning of a reinforced concrete structure is the set of activities of projects that leads to the determination of the dimensions of the pieces and later steel reinforcements, as well as the detailing of these reinforcements inside the pieces and their connections, in order to support the actions building. This process shall comply with the provisions of the relevant technical standards, so that the structure has an adequate safety guarantee at break and a good progress under the intended conditions of use. For the general purpose, the purpose of this work is the realization with the help of the software Eberick, the structural design of a single-family residence of two floors in reinforced concrete. The methodology of this work was based on bibliographic research in books, technical standards, articles; thus providing all its theoretical and normative foundation for all the stages present in this Course Conclusion Work.

Keywords: Eberick. Structural design. Reinforced concrete.

\section{INTRODUÇÃO}

No mercado brasileiro há vários softwares computacionais com a finalidade de ser uma ferramenta bastante útil ao calculista na hora da concepção do projeto estrutural, todavia não se deve esquecer, que o software não trabalha sozinho, por trás dele deve existir um profissional com extrema capacidade e sabedoria para saber usá-lo de maneira eficaz, para que a obra não fique superdimensionada e nem subdimensionada, obtendo assim, maior segurança e economia através de um projeto bem elaborado.

Para projetar estruturas usando o concreto armado, requer que o profissional tenha boa perspectiva sobre algumas áreas das ciências, como a química dos materiais, conceito de mecânica dos sólidos deformáveis e a teoria geral das estruturas ou de forma mais superficial, mas necessária, ele deve estar 
familiarizado com assuntos da dinâmica das estruturas, mecânica dos solos, teoria da plasticidade, etc. Tudo isso para que compreenda com mais facilidade as interrelações que esses fenômenos tem com seus projetos estruturais, seja em forma da interação com ações envolvidas, ou para compreender aspectos ligados à corrosão, à fissuração, à concentração de tensões, etc (PORTO; FERNANDES, 2015).

O cálculo ou dimensionamento de uma estrutura de concreto armado se entende como o conjunto de atividades de projeto que conduz à determinação das dimensões das peças e provenientes armaduras de aço, assim como, o detalhamento da disposição dessas armaduras, no interior das peças e em suas ligações, a fim de suportar as ações atuantes na edificação. Este processo deve atender às disposições das normas técnicas pertinentes, para que a estrutura tenha uma garantia adequada de segurança à ruptura e um bom andamento sob as condições previstas de utilização (CLÍMACO, 2008).

Um item que é de suma importância para entender o que se deseja obter da construção é a etapa de análise do projeto arquitetônico. A concepção geral de uma obra no espaço é determinada por meios do projeto arquitetônico. Nesta análise deve-se também efetuar uma verificação das distâncias cotadas nas plantas, cortes e vistas, evitando-se a propagação das possíveis anomalias existentes, o que comprometeria o projeto da edificação. Anteprojeto estrutural, é a concepção estrutural propriamente dita, onde modula-se a arquitetura idealizada e onde se define a forma da estrutura (NÓBREGA, [20-]).

Com o passar dos anos, e com a evolução global socioeconômica, o crescimento populacional foi inevitável, logo, para acomodar tantas pessoas, o aumento de habitações foi crescendo na mesma proporção, e com isso, novas técnicas de construção foram empregadas, novas tecnologias nos métodos construtivos foram descobertas e novos profissionais da engenharia foram aparecendo. Com isso, a necessidade de se haver um projeto para uma edificação ficou cada vez mais evidente.

Mas na contramão do processo evolutivo das edificações, muitas pessoas ainda têm o hábito de construir por conta própria, sem projeto e o amparo de um engenheiro para thes fornecer um bom projeto estrutural, ora por inviabilidade econômica, ora pela autoconfiança, ou até mesmo pelo compilado destes motivos. 
Com estes fatos expostos, claros e contundentes, vem à tona o questionamento: qual a real importância de um projeto estrutural, para uma edificação de uso residencial construída em concreto armado?

Para nortear essa pergunta, este trabalho busca não apenas respondê-la de forma categórica, como também, realizar o dimensionamento e detalhamento de uma edificação para fins residenciais construída em concreto armado, afirmando de fato que todo o material didático e conhecimento prático passado em sala de aula foi absorvido com clareza.

Para o objetivo geral, tem-se como meta realizar com o amparo do software Eberick, o dimensionamento estrutural de uma residência unifamiliar de 02 pavimentos em concreto armado. Para efeitos de cálculo, as fundações serão necessárias para o lançamento da estrutura, mas não terão ênfase neste trabalho, pois, não se tem um laudo de sondagem do terreno para poder definir qual tipo de fundação melhor se enquadra no projeto, portanto, não serão detalhadas. Contudo, a seguir seguem os objetivos específicos:

a) Formalizar a concepção da estrutura através do projeto arquitetônico;

b) Lançar a estrutura por meios de um pré-dimensionamento no software (Eberick);

c) Após os resultados obtidos pelo programa, fazer uma síntese geral e análise da estrutura;

d) Proceder com o detalhamento da estrutura.

A metodologia deste trabalho teve como base pesquisas bibliográficas em livros, normas técnicas, artigos; assim fornecendo todo o seu embasamento teórico e normativo para todas as etapas presentes neste Trabalho de Conclusão de Curso.

\section{DESENVOLVIMENTO}

O referencial teórico foi abordado para fundamentar os objetivos desta pesquisa. 


\section{O QUE É O CONCRETO}

É a uma combinação de materiais, constituído basicamente de agregados e cimento como aglutinante; é portanto um tipo de rocha artificial. A fabricação do concreto é feita pela mistura de agregados, estes sendo a areia, brita, cimento e água, à qual conforme a necessidade, são acrescentados aditivos, que influenciam as características físicas e químicas do concreto (LEONHARDT; MÖNNING, 1972).

Utilizado na construção civil, o concreto é um material composto por agregados graúdos (pedra brita), agregados miúdos (areia natural ou artificial), aglomerantes (cimento), água, adições minerais e aditivos (PORTO; FERNANDES, 2015).

Por apresentar boa resistência à compressão, mas não à tração, utilizar o concreto simples se torna muito limitado. Quando se faz necessária a resistência aos esforços de compressão e tração, associa-se o concreto a materiais que apresentem alta resistência à tração, dando origem ao concreto armado (PORTO; FERNANDES, 2015).

\section{As primeiras utilizações do concreto armado no Brasil}

Em nosso país, não se tem muitas notícias sobre o início da utilização do concreto armado. A notícia mais antiga sobre o seu emprego data de 1904, no Rio de Janeiro, diz-se que o cimento armado (como era chamado na época) foi utilizado pela primeira vez no Brasil nas construções habitacionais de Copacabana pela "Empreza de Construcções Civis", sob responsabilidade do engenheiro Carlos Poma (PORTO; FERNANDES, 2015).

\section{Conceitos Fundamentais}

Segundo Carvalho e Figueiredo Filho (2015) basicamente, o concreto é formado de água, agregados e cimento. Homogeneizando estes materiais temos:
a) Pasta: cimento mais água;
b) Argamassa: pasta + agregado miúdo;
c) Concreto: argamassa + agregado graúdo. 


\section{Vantagens do Concreto}

É de fácil adaptabilidade nas formas, pode ser usado em estado semifluido, o que abre possibilidades para a elaboração arquitetônica. Os aditivos plastificantes e fluidificantes que comumente são usados para aumentar a trabalhabilidade e fluidez do concreto, possibilitam que o mesmo seja bombeado através de mangotes sob pressão, para grandes alturas, com redução significativa entre custos e prazos nas tarefas de transporte e lançamento (CLíMACO, 2008).

As principais vantagens são de uma resistência mais elevada à maioria das suas solicitações, tem boa trabalhabilidade, em todos os cantos do país existe mão de obra de fácil acesso, é considerado um material durável, tem boa durabilidade e boa resistência quando submetido ao fogo comparado à outros materiais, entre outros (CARVALHO; FIGUEIREDO FILHO, 2015).

\section{Desvantagens}

O concreto tem um peso próprio bem elevado (massa específica=2.500 $\mathrm{kg} / \mathrm{m}^{3}$ ), obter de outros tipos de concreto, como o concreto leve, é tecnicamente viável para fins estruturais, com a substituição da brita comum, por agregados leves, como a argila expandida. Por parte da massa específica, a redução é significativa, chegando à um valor de $1600 \mathrm{~kg} / \mathrm{m}^{3}$. No entanto, esses agregados geram um custo mais elevado, para o emprego de obras convencionais, além de ser necessário avaliar melhor os aspectos de durabilidade, pois, esses concretos tendem à ser mais porosos (CLÍMACO, 2008).

\section{Consistência da mistura}

A primeira propriedade que se deverá ser levada em consideração é a consistência, que corresponde na capacidade de maior ou menor chance em que o concreto tem em se deformar. Pode estar associada às condições de transporte, lançamentos e o adensamento do concreto, que pode variar de acordo com a granulometria dos materiais, pelo uso de produtos químicos, e pela quantidade de água na mistura (CARVALHO; FIGUEIREDO FILHO, 2015). 


\section{Trabalhabilidade do concreto}

O concreto tem várias finalidades, cada uma tendo a sua característica de trabalhabilidade, conforme explica Bauer (2015, p. 273) "Ao se discutir a trabalhabilidade de um concreto em termos gerais, está implícita a necessidade de que a mistura seja estável, não segregue facilmente [...]".

No mesmo segmento desta afirmação, existe o slump test, que é um teste que mede a consistência do concreto, afim de averiguar a trabalhabilidade do concreto para um determinado elemento a ser concretado.

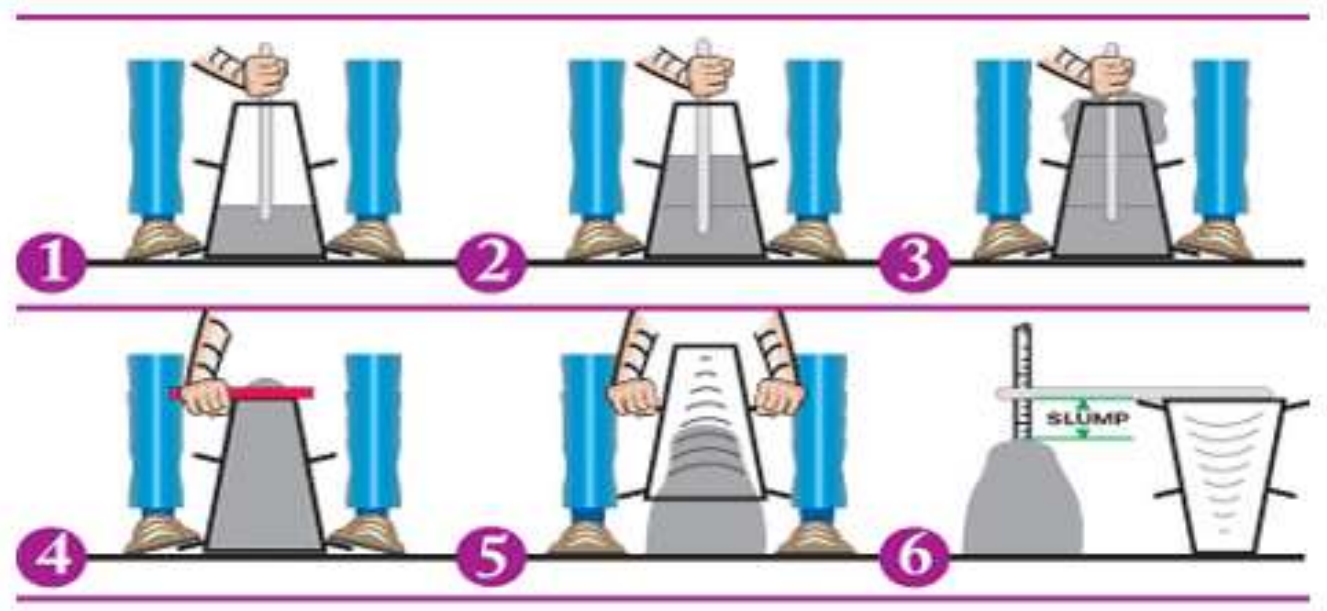

Figura 5: slump test

Fonte: The Constructor (2017)

\section{A homogeneidade dentro da massa}

$\mathrm{Na}$ qualidade do concreto, um fator que tem peso importante é a distribuição dos agregados graúdos. Se forem uniformes, ou regulares, os agregados graúdos se apresentarem dispersos na massa, a qualidade do concreto será melhor, principalmente no que diz respeito à permeabilidade, proporcionando proteção à armadura, além de resultar em um melhor acabamento da superfície, sem a necessidade de posteriores reparos. Essa compatibilização dos agregados é a homogeneidade; portanto, quanto mais homogêneo o concreto, melhor a qualidade da estrutura (CARVALHO; FIGUEIREDO FILHO, 2015). 
ESTADO LIMITE

Conforme Carvalho e Figueiredo Filho (2015, p. 52), "Os estados limites considerados no cálculo das estruturas de concreto são os estados limites últimos e os estados limites de serviço".

\section{Estado limite último}

Segundo Carvalho e Figueiredo Filho (2015, p. 52), "O estado limite último é aquele relacionado ao colapso ou a qualquer outra forma de ruína estrutural que determine a paralisação, no todo ou em parte, do uso da estrutura".

\section{Estado limite de serviço}

Segundo a NBR 6118 (ABNT, 2014, p. 50), "Estados limites de serviço são aqueles relacionados à durabilidade das estruturas, aparência, conforto do usuário e à boa utilização funcional das mesmas, seja em relação aos usuários, seja em relação às máquinas e aos equipamentos utilizados".

\section{ELEMENTOS ESTRUTURAIS BÁSICOS}

Temos como elementos estruturais básicos, as fundações, pilares, vigas e lajes, respectivamente.

\section{Fundações}

Um dos principais elementos de uma estrutura são as fundações, que são responsáveis por transmitir a carga da edificação até o solo. Para escolher o tipo mais adequado de uma fundação, deve-se levar em conta as condições do solo e as cargas atuantes na fundação que vai ser executada, com o objetivo de dissipar as cargas ao solo sem causar a ruptura do mesmo (PORTO; FERNANDES, 2015).

\section{Fundações superficiais}

De acordo com a NBR 6122 (2010 apud PORTO; FERNANDES, 2015), as fundações superficiais, as cargas são levadas até o solo, pelas tensões sob a base 
da fundação, esta, estando em uma profundidade de no máximo, o dobro da menor dimensão do elemento de fundação.

Esses tipos de fundações são comumente mais baratas e de execução mais descomplicada que as demais fundações, estão geralmente à uma profundidade de no máximo 2,0 metros, e são utilizados quando o solo apresenta boa resistência (PORTO; FERNANDES, 2015).

Neste contexto temos as sapatas isoladas, associadas ou corridas, radier e baldrame, sendo cada uma utilizada de acordo com as condições do terreno (PORTO; FERNANDES, 2015).

Fundações profundas

As fundações denominadas profundas, são elementos estruturais dos quais as cargas são transmitidas ao solo pela base, pelo atrito entre sua superfície lateral e o solo, ou pelos dois métodos, possuindo uma profundidade se assentamento superior ao dobro da menor medida em planta do elemento (PORTO; FERNANDES, 2015).

Essas fundações podem sem moldadas in loco, quando se faz a perfuração do solo com equipamentos adequados e execução do elemento de fundação, ou pré-moldadas, quando são cravadas no terreno por um equipamento específico. São indicadas quando a resistência ideal do solo se encontra em uma profundidade muito grande (PORTO; FERNANDES, 2015).

Os tipos de fundações profundas mais utilizadas são: tubulão, estacas e caixões.

\section{Pilares}

Os pilares são elementos preponderantemente comprimidos e usados comumente na posição vertical. Eles são os responsáveis por sustentar as cargas vindas das vigas e lajes, conduzindo estas cargas até as fundações (GRAZIANO, 2005).

"Como os pilares são responsáveis pelo suporte de outros elementos estruturais, sua importância ao equilíbrio é incontestável, devendo receber um 
tratamento de maior cuidado no projeto e execução" (GRAZIANO, 2005, p.68).

\section{Vigas}

São elementos estruturais solicitados normalmente à flexão e que geometricamente mantém uma relação entre vão e altura, para vigas isostáticas, $L / h>3,0$ e, para vigas contínuas, de $L / h>2,0$, sendo $L$ o comprimento do vão teórico e $\mathrm{h}$ a altura total da viga. A relação altura/largura da seção deverá ser menor ou igual a 5 (GRAZIANO, 2005).

\section{Lajes}

"Lajes são elementos planos e laminares que estão sujeitos principalmente à forças, segundo a direção normal ao seu plano" (GRAZIANO, 2005, p.117).

"Nestas condições, as lajes estão preponderantemente flexionadas e podem ser classificadas de acordo com a direção em que estas flexões ocorrem" (GRAZIANO, 2005, p.117).

Segundo Graziano (2005, p.117):

a) Lajes armadas em uma só direção, são aquelas que, do ponto de vista do modelo estrutural, estão fletidas apenas em uma direção;

Lajes armadas em cruz, são aquelas que se encontram fletidas em duas direções ortogonais entre si.

\section{IDENTIFICAÇÃO DA OBRA E PROJETO}

Este trabalho trata-se apenas de um dimensionamento estrutural hipotético, para fins acadêmicos.

A obra está localizada na cidade de Fraiburgo/SC, no bairro das Hortênsias, rua das flores. O terreno onde está o empreendimento tem uma área total de $612,81 \mathrm{~m}^{2}$. Segue a figura 2 , da imagem aérea do terreno. 


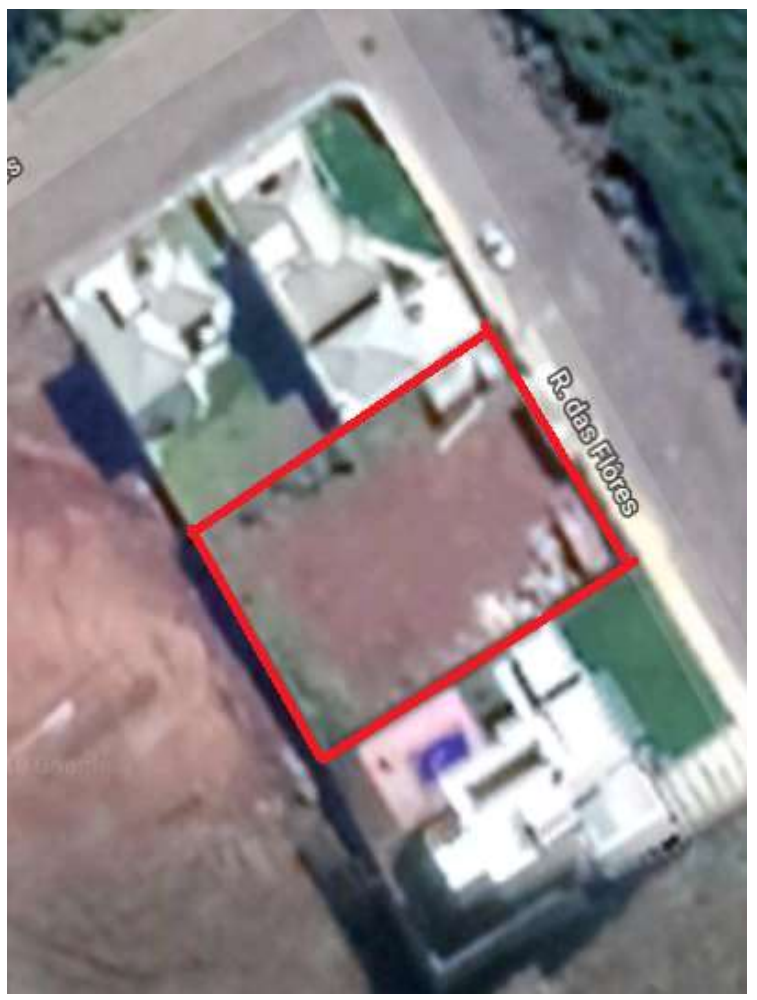

Figura 6: Localização do terreno

Fonte: Google Maps (2018)

Para o estudo proposto, utilizou-se o projeto arquitetônico de autoria do Engenheiro Civil Kleiton Pasini (2018). Este projeto será usado somente para fins acadêmicos, já que, é uma obra que se encontra conclúida, onde foi construída em concreto armado.

A edificação proposta neste trabalho tem dois pavimentos, com uma área total construída de $294,15 \mathrm{~m}^{2}$, sendo $180,30 \mathrm{~m}^{2}$ no pavimento térreo e $113,85 \mathrm{~m}^{2}$ no pavimento superior. A figura à seguir mostra a fachada da edificação. 


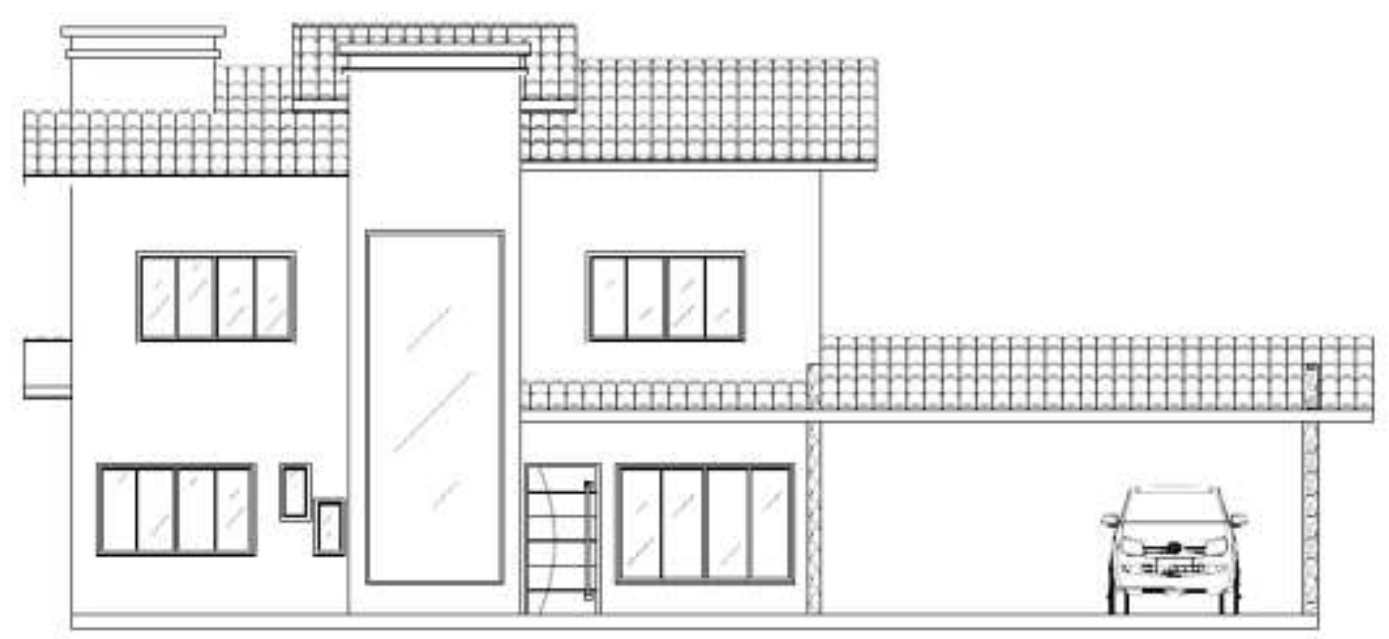

Figura 7: Fachada

Fonte: Pasini Engenharia (2018)

MATERIAIS

Neste trabalho, foram usados dois softwares, AutoCad e Eberick. O AutoCad é um software desenvolvido pela empresa Autodesk, que basicamente contém um conjunto de ferramentas que auxiliam no desenvolvimento de desenhos técnicos para diferentes áreas, neste caso, a civil. E é com a ajuda deste software que será feito o embasamento arquitetônico do projeto em estudo, levando em consideração principalmente a planta baixa, cortes e fachada.

O Eberick é um software desenvolvido pela empresa AutoQi, com a finalidade do dimensionamento estrutural em concreto armado, englobando etapas como o lançamento da estrutura, análise, dimensionamento e o detalhamento dos elementos estruturais. O lançamento da estrutura é feito através do AutoCad, considerando os itens já mencionados. Estes dois softwares trabalhando em conjunto auxiliam os profissionais calculistas e projetistas de maneira muito eficaz.

\section{DIRETRIZES DO LANÇAMENTO E ANÁLISE}

Em todos os pavimentos, a seção mínima das vigas e pilares lançados no 
pré-dimensionamento foi de acordo com a norma NBR 6118 (ABNT, 2014), onde diz que os pilares devem ter seção mínima transversal de $360 \mathrm{~cm}^{2}$, sendo lançados em todos os pavimentos com $14 \times 30 \mathrm{~cm}$. Já as vigas foram todas lançadas inicialmente com seção de $14 \times 40 \mathrm{~cm}$, do qual, segundo a norma, vigas devem ter a medida mínima no menor lado da seção com $12 \mathrm{~cm}$. As vigas que recebem cargas das lajes bem como de paredes, foram lançadas com carga extra de parede, no valor de $468 \mathrm{kgf} / \mathrm{m}$.

No pavimento térreo, as lajes foram lançadas como maciças, com espessura de $12 \mathrm{~cm}$, com carga acidental e revestimento de $150 \mathrm{kgf} / \mathrm{m}^{2}$, com exceção das lajes da garagem, que foram lançadas com carga acidental de $500 \mathrm{kgf} / \mathrm{m}^{2}$. No pavimento teto do térreo, e no pavimento teto do segundo pavimento, as lajes foram lançadas como pré-moldadas, com vigotas de $08 \mathrm{~cm}$ de altura, e enchimentos de EPS com medidas de $08 \times 30 \times 125 \mathrm{~cm}$, e capa de concreto de $5 \mathrm{~cm}$, totalizando $\mathrm{h}=13 \mathrm{~cm}$. Todas as lajes destes dois pavimentos foram lançadas com cargas acidentais e de revestimento com $150 \mathrm{kgf} / \mathrm{m}^{2}$.

Os lances de escadas e o patamar, foram lançados com $10 \mathrm{~cm}$ de espessura e carga acidental de $250 \mathrm{kgf} / \mathrm{m}^{2}$, e de $250 \mathrm{kgf} / \mathrm{m}^{2}$ para revestimento.

A laje da caixa d'água foi lançada como maciça, de $12 \mathrm{~cm}$ de espessura, com carga acidental de $600 \mathrm{kgf} / \mathrm{m}^{2}$, e $50 \mathrm{kgf} / \mathrm{m}^{2}$ para revestimento.

Após lançada a estrutura, esta, foi processada para verificar se os elementos arbitrados atenderiam as suas solicitações, onde foram obtidos os seguintes resultados: As vigas baldrame, passaram todas com as medidas iniciais de lançamento, $14 \times 40 \mathrm{~cm}$, sem precisar de nenhuma alteração.

As lajes do pavimento térreo passaram com a altura inicial de lançamento, $12 \mathrm{~cm}$, sem precisar de nenhuma alteração. Alguns pilares inicialmente não passaram, onde todos apresentaram o mesmo erro, conforme mostra a figura 4, onde observou-se que os erros foram em função dos esforços de momento atuante no lado de menor inércia do pilar, onde a solução foi aumentar o lado da seção com o problema. 


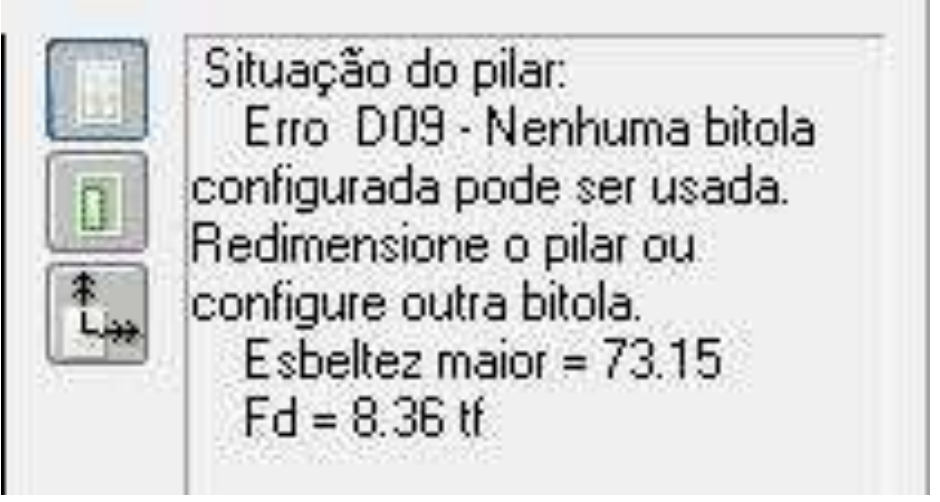

Figura 8: Erro dos pilares

Fonte: O próprio autor

As vigas dos demais pavimentos que tiveram erro, foram somente as vigas que servem de apoio para outras vigas, gerando torção, haja vista que no momento do lançamento o programa às pré-define como engastadas. Para corrigir essa torção gerada pelas vigas que são apoiadas por outras vigas, foram alterados os tipos do apoio, passando de engastado para rotulado, solucionando assim o problema. A figura 5 mostra uma viga apoiada em outra com um apoio rotulado.

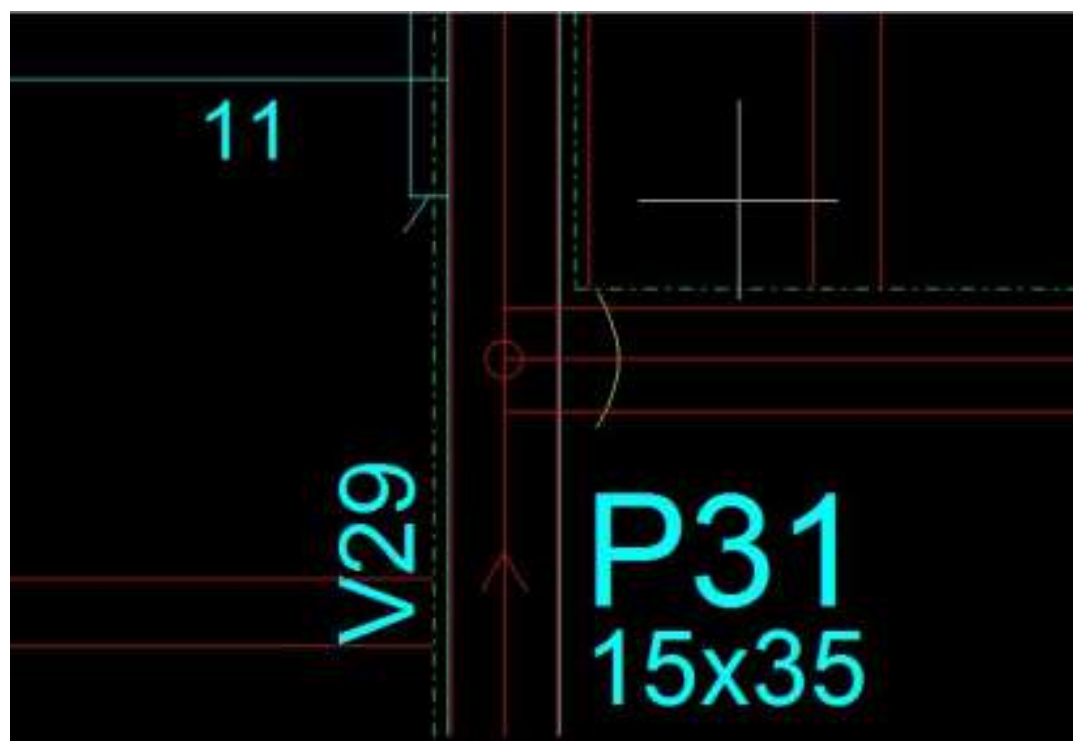

Figura 9: Viga Rotulada

Fonte: O próprio autor 


\section{CONCLUSÃO}

Toda edificação quando concebida, deve-se levar em consideração um item que é de suma importância, o projeto estrutural. É este projeto que vai garantir a segurança da estrutura contra possíveis avarias, como rachaduras indesejadas, e até mesmo um possível colapso da estrutura.

O calculista deve ter afinidade também com o projeto arquitetônico, que é a partir deste projeto que se definem os melhores locais para posicionar os pilares e vigas, garantindo assim a segurança da estrutura sem comprometer a arquitetura da edificação.

Este trabalho teve como abordagem todo o conhecimento análogo às disciplinas vistas ao longo do curso referentes ao dimensionamento de projeto estrutural em concreto armado, com o propósito de conceber o projeto estrutural de uma residência de dois pavimentos construída em alvenaria tradicional, com o auxílio do software Eberick, programa computacional de lançamento de estruturas em concreto armado, destinado aos profissionais da Engenharia, produzido com o intuito de melhorar a concepção de um projeto estrutural, levando em consideração principalmente o tempo levado para a construção do projeto.

Nesta pesquisa foram abordadas diferentes etapas sobre o projeto estrutural, partindo de um pequeno histórico do concreto armado no Brasil, das propriedades do concreto armado, normas, materiais à serem utilizados, identificação da obra, projeto, chegando então aos resultados finais do dimensionamento, mostrando que o projeto estrutural é fundamental, para manter a segurança da estrutura e também para evitar custos onerosos em virtude de uma obra má executada e sem projeto estrutural.

\section{REFERÊNCIAS}

ADÃO, Francisco Chavier; HEMERLY, Adriano Chequetto. Concreto armado: novo milênio cálculo prático e econômico. 1. ed. Rio de Janeiro: Interciência Ltda, 2010.

AZEREDO, Hélio Alves de. O edifício até sua cobertura. 2. ed. São Paulo: Blucher, 1997. 
ASSOCIAÇÃO BRASILEIRA DE NORMAS TÉCNICAS. NBR 6118: Projeto De Estruturas De Concreto - Procedimento. Rio de Janeiro, 2014.

ASSOCIAÇÃO BRASILEIRA DE NORMAS TÉCNICAS. NBR 6120: Cargas para o cálculo de estruturas de edificações - Procedimento. Rio de Janeiro, 1980

ASSOCIAÇÃO BRASILEIRA DE NORMAS TÉCNICAS. NBR 9935: Agregados Terminologia. Rio de Janeiro, 2011.

BAUER, Luiz Alfredo Falcão. Materiais de construção. 1. ed. Local: Livros Técnicos e Científicos, 2015.

BASTOS, Paulo Sérgio dos Santos. Fundamentos do concreto armado. 2016. 98 f. Dissertação (Mestrado) - Curso de Mestrado em Engenharia Civil. UNESP, Universidade Estadual Paulista "Júlio de Mesquita Filho", Bauru.

BOTELHO, Manoel Henrique Campos; MARCHETTI, Osvaldemar. Concreto armado eu te amo. 8. ed. São Paulo: Edgard Blücher Ltda, 2015.

CARVALHO, Roberto Chust; FIGUEIREDO FILHO, Jasson Rodrigues de. Cálculo e detalhamento de estruturas usuais de concreto armado. 4. ed. São Carlos: Edufscar, 2015.

CLÍMACO, João Carlos Teatini de Souza. Estruturas de concreto armado: fundamentos de projeto, dimensionamento e verificação. 2. ed. Brasília: Unb, 2008.

GOOGLE maps. Disponível em:

$<$ https://www.google.com.br/maps/place/R.+das+Fl\%C3\%B4res+-

+Jardim+DAS+HORT\%C3\%8ANCIAS,+Fraiburgo+-+SC,+89580-000/@-27.6372997,$51.1482922,123937 \mathrm{~m} / \mathrm{data}=! 3 \mathrm{~m} 1 ! 1 \mathrm{e} 3 ! 4 \mathrm{~m} 5 ! 3 \mathrm{~m} 4 ! 1 \mathrm{~s} 0 \times 94 \mathrm{e} 1397 \mathrm{ddb} 7 \mathrm{~d} 83 \mathrm{a3}: 0 \times a 4 \mathrm{c}$ 089a7ba412f7f!8m2!3d-27.0288726!4d-50.9298252>. Acesso em: 24 out. 2018.

GRAZIANO, Francisco Paulo. Projeto e execução de estruturas de concreto armado. São Paulo: O Nome da Rosa, 2005.

LEET, Kenneth M.; UANG, Chia M.; GILBERT, Anne M. Fundamentos da Análise Estrutural-3. Local: AMGH Editora, 2014.

LEONHARDT, Fritz; MÖNNING, Eduard. Construções de concreto. Stuttgart: Interciência, 1972. 
MISHRA, Gopal. The constructor. Disponível em:

$<$ https://theconstructor.org/concrete/concrete-slump-test/1558/>. Acesso em: 16 out. 2018.

PAZINI, Kleiton. Projeto Arquitetônico, 2018.

PORTELA, Régis. Tipos de apoio. Disponível em:

$<$ https://pt.slideshare.net/REGISPORTELA/estruturas-02>. Acesso em: 03 jun. 2018.

PORTO, Thiago Bomjardim; FERNANDES, Danielle Stefane Gualberto. Curso básico de concreto armado. São Paulo: Oficina de Textos, 2015. 